\section{Commentary: Great toenail grafts for tracheal reconstruction: Adopt it or kick it to the curb- your choice}

\section{Robert B. Cameron, MD}

Although organ transplantation has been successful for a variety of organs, the trachea is not one of them. Furthermore, biologic and tissue-engineered tracheal replacements have suffered from a pandemic of overly simplistic concepts regarding the use of tissue scaffolds and stem cells as well as patently fraudulent claims of success. ${ }^{1,2}$ The main challenges for tracheal transplants/replacements stem from the trachea's lack of an anastomosable blood supply and simultaneously its exposure to the outside contaminated world. Clearly, more work is required before thoracic surgeons routinely are able to replace large segments of airway; however, resection of more limited segments and reconstruction of portions of the airways currently are and remain viable options.

In this issue of JTCVS Techniques, Huang and colleagues ${ }^{3}$ describe a novel method of reconstructing limited tracheobronchial airway defects. Four cases illustrate the use of toenail grafts in the reconstruction of the anterolateral airway. Three patients had tracheostomy-site issues (stenosis, malacia, and nonhealing) whereas the fourth had a focal right lateral tracheal wall defect from resection of a lymph node with metastatic lung cancer. All were repaired successfully with toenail grafts. An instructional video, which accompanies the paper, demonstrates this rather novel approach, and toenail harvesting, something likely foreign

From the Division of Thoracic Surgery, Department of Surgery, David Geffen School of Medicine at UCLA and Division of Thoracic Surgery, Department of Surgery and Perioperative Care, West Los Angeles VA Medical Center, Los Angeles, Calif. Disclosures: The author reported no conflicts of interest.

The Journal policy requires editors and reviewers to disclose conflicts of interest and to decline handling or reviewing manuscripts for which they may have a conflict of interest. The editors and reviewers of this article have no conflicts of interest.

Received for publication Nov 1, 2021; revisions received Nov 1, 2021; accepted for publication Nov 5, 2021; available ahead of print Nov 10, 2021.

Address for reprints: Robert B. Cameron, MD, Division of Thoracic Surgery, Department of Surgery, David Geffen School of Medicine, Center for the Health Sciences, Room 64-132, Box 957313, 10833 Le Conte Ave, Los Angeles, CA 90095-7313 (E-mail: rcameron@stanfordalumni.org).

JTCVS Techniques 2022;11:96-7

2666-2507

Copyright (C) 2021 The Author(s). Published by Elsevier Inc. on behalf of The American Association for Thoracic Surgery. This is an open access article under the CC BY-NC-ND license (http://creativecommons.org/licenses/by-nc-nd/4.0/).

https://doi.org/10.1016/j.xjtc.2021.11.007

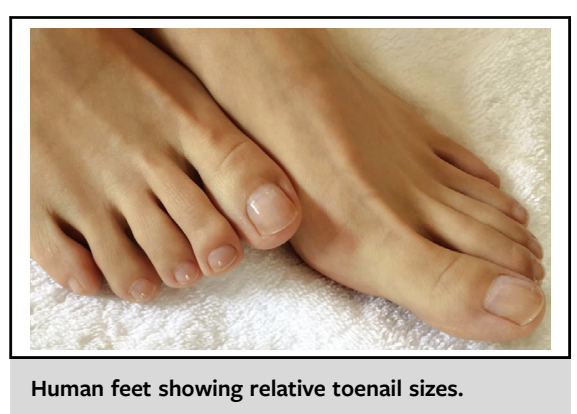

CENTRAL MESSAGE

Toenail grafts harvested from the great toe are novel and hold potential for use in airway reconstructive surgery but require more clinical experience and data.

to most thoracic surgeons, is described in detail. Toenails from the great toe (Figure 1) are preferred due to obvious size advantages. Other advantages of using great toenail grafts include the use of tissue, specifically autologous tissue, grafts as well as tissue that can mimic the strength and curvature of the native tracheal/bronchial wall. The authors also claim that the grafts appeared to be covered with respiratory epithelium (no biopsies were taken) as early as 1 month postoperatively and appeared to resist normal wound contraction and airway narrowing - at least in one patient. Further, toenails are a renewal resource, with the toenails regenerating with a period of approximately 2 months.

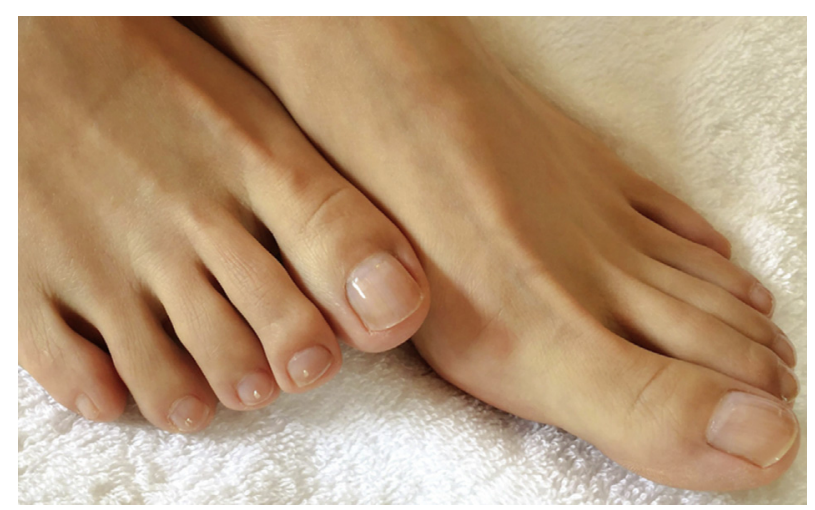

FIGURE 1. Human feet showing relative toenail sizes (CB 3762 Studio; licensed from Shutterstock.com). 
Certainly, the authors should be congratulated for thinking "out of the box," but before all tracheal surgeons can "high-five," some realities need to be acknowledged. First, the grafts are very limited in size and number (a maximum of 2 great toenails every 2 months) and can repair only rather small airway defects. Also similar results potentially could be obtained equally with several other existing reconstructive techniques. Furthermore, many older patients requiring airway surgery may not be optimal candidates for toenail harvesting due to diabetes mellitus, vascular disease, fungal infections, and/or lower-extremity amputation/injury. Unquestionably, this technique is intriguing, but it needs more clinical study. Yet, it may be worth considering for that occasional high-risk patient who has a high subglottic tracheal stenosis and other significant risk factors. Such patients may be helped by a relatively lower-risk anterior midline split/resection with toenail reconstruction, similar to patient 4 in Huang and colleagues' report, rather than a difficult segmental resection and high glottic anastomosis. An idea to keep in your repertoire or to kick to the curb-your choice.

\section{References}

1. Fux T, Österholm C, Themudo R, Simonson O, Grinnemo KH, Corbascio M Synthetic tracheal grafts seeded with bone marrow cells fail to generate functional tracheae: first long-term follow-up study. J Thorac Cardiovasc Surg. 2020;159: 2525-37.e23.

2. The Lancet. The final verdict on Paolo Macchiarini: guilty of misconduct. Lancet 2018;392:2.

3. Huang HF, Hwang JJ, Huang PM. Tracheal reconstruction with nail grafts: a novel approach. J Thorac Cardiovasc Surg Tech. 2021;10C:554-60. 